\title{
Fabrication and Characterization of Porous Hydroxyapatite Scaffolds
}

\author{
Minsung Kim, Ih-Ho Park and Byong-Taek Lee ${ }^{\dagger}$ \\ Department of Biomedical Engineering Engineering and Materials, School of Medicine, Soonchunhyang University, \\ 366-1, Ssangyoung-dong, Cheonan-City, Chungnam 330-090, South Korea.
}

(Received July 20, 2009 : Received in revised form October 30, 2009 : Accepted December 1, 2009)

\begin{abstract}
Using a polyurethane foam replica method, porous hydroxyapatite scaffolds (PHS) were fabricated using conventional and microwave sintering techniques. The microstructure and material properties of the PHS, such as pore size, grain size, relative density and compressive strength, were investigated at different sintering temperatures and holding times to determine the optimal sintering conditions. There were interconnected pores whose sizes ranged between about $300 \mu \mathrm{m}$ and $700 \mu \mathrm{m}$. At a conventional sintering temperature of $1100^{\circ} \mathrm{C}$, the scaffold had a porous microstructure, which became denser and saw the occurrence of grain growth when the temperature was increased up to $1300^{\circ} \mathrm{C}$. In the case of microwave sintering, even at low sintering temperature and short holding time the microstructure was much denser and had smaller grains. As the holding time of the microwave sintering was increased, higher densification was observed and also the relative density and compressive strength increased. The compressive strength values of PHS were $2.3 \mathrm{MPa}$ and $1.8 \mathrm{MPa}$ when conventional and microwave sintering was applied at $1300^{\circ} \mathrm{C}$, respectively.
\end{abstract}

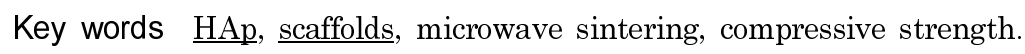

\section{Introduction}

Scaffolds for bone tissue engineering have become an active area of research because scaffolds lie at the heart of all new tissue engineering approaches. ${ }^{1,2)}$ Various synthetic alternatives, such as ceramics, polymers and composites, have been extensively examined as scaffolds over many years. ${ }^{3,4)}$ Regarding the scaffolds, it is generally believed that a highly porous microstructure with interconnected pores and a large surface area is conducive to the growth of hard tissues. ${ }^{5-7)}$ However, satisfactory scaffolds should not only have the appropriate porosity but also mechanical properties. Only if they have the proper mechanical properties can the scaffolds maintain their functionalities after being implanted into the body. ${ }^{8-10)}$

Ceramics that are used to repair and reconstruct diseased or damaged parts of the human body have been called bioceramics. The use of hydroxyapatite (HAp, with $\mathrm{Ca} / \mathrm{P}$ $=1.667$ ) as fillers, spacers and bone graft substitutes have significantly increased over the past two decades due to the growing demands for bioactive materials for orthopedic as well as maxillofacial surgery. The primary reason for the increased use of HAp based bioceramics is because

Corresponding author

E-Mail : lbt@sch.ac.kr (B. -T. Lee) of its biocompatibility, bioactivity, and osteoconduction characteristics with respect to the host tissue. ${ }^{11-13)}$ Recently, researchers have attempted to fabricate HAp scaffolds using the replica method. However, there are critical limitations in applying HAp scaffolds to a real system because of its low compressive strength. ${ }^{14,15)}$

On the other hand, microwave heating is a fast sintering process that is fundamentally different from conventional electric heating techniques in that the energy can be provided to the whole material volumetrically rather than relying on thermal conduction from the surface. Proper use of this technique may lead to a series of benefits, including greater microstructure control, improved product properties and reduced manufacture costs due to the saved energy and reduced processing time; thus, microwave sintering is a highly promising alternative method for ceramic processing. During the last 15 years, microwave processing of ceramic materials, which ranged from structural ceramics to functional ceramics, has been widely investigated by various researchers; ${ }^{16-18)}$ however, there have been only a limited number of studies that examined microwave sintering of bioceramics. ${ }^{19,20)}$

In this work, a porous hydroxyapatite scaffolds (PHS) was fabricated by the replica method using polyurethane foam, which has a similar structure to cancellous bone. A subsequent thermal treatment step was used to remove 
the organic materials remaining in the HAp ceramic in the substratum. Two different kinds of sintering methods were used and compared; microwave sintering and conventional sintering. The mechanical properties and microstructures of PHS produced using these techniques were then characterized.

\section{Experimental Procedure}

The porous HAp scaffolds were fabricated by the polyurethane foam replica method using two kinds of sintering processes; microwave sintering and conventional sintering. ${ }^{21)}$ The coating slurry was prepared from HAp powder (aver. size, 10 30 nm), which was synthesized by the microwave-hydrothermal method. ${ }^{22)}$ Fifty grams of HAp powder were stirred vigorously in $100 \mathrm{ml}$ of alcohol for 4h. As a binder, $5 \mathrm{~g}$ poly vinyl butyl (PVB, Acros, USA) was dissolved in another beaker for $1 \mathrm{~h}$, which was subsequently added to the slurry and stirred for an additional 24h. Polyurethane foam templates (60ppi, SY I\&C, Korea) cut to appropriate dimensions were immersed in the slurry. After blowing with an air gun to disperse the slurry uniformly throughout the porous scaffolds without blocking the pores, the sponge was dried at $80^{\circ} \mathrm{C}$ for $8 \mathrm{~h}$. These dipping-and-drying steps were repeated three times. The obtained body was heat-treated to burn out the sponge and binder at $600^{\circ} \mathrm{C}$ for $3 \mathrm{~h}$ in air at a heating rate of $1^{\circ} \mathrm{C} /$ min. A microwave furnace (UMF-01, Unicera, Korea) was then used to sinter the scaffolds at a heating rate of $45^{\circ} \mathrm{C} /$ min and at different temperatures $\left(1100^{\circ} \mathrm{C}, 1200^{\circ} \mathrm{C}, 1300^{\circ} \mathrm{C}\right)$ and holding times $(5,10,15,20$, and 30 minutes). The microwave furnace used in this work adopted the MicroTime-Slicing mechanism. This mechanism controls the cycle of magnetron On/Off in microscopic time. The cycle of the Micro-Time-Slicing mechanism is smaller than 0.001 second, which is much shorter than the cycle of the conventional On/Off mechanism. Thus, the temperature deviation problem did not occur and it was very stable to maintain high temperatures. Conventional sintering was also performed at different temperatures $\left(1100^{\circ} \mathrm{C}, 1200^{\circ} \mathrm{C}\right.$, $1300^{\circ} \mathrm{C}$ ) for 3 hours at a heating rate of $5^{\circ} \mathrm{C} / \mathrm{min}$.

The relative density of PHS was measured using the Archimedes method. To identify the crystal structure and phases of the samples, X-ray diffraction (XRD, D/MAX250 , Rigaku, Japan) was employed by crushing the sample into powder. To investigate the pore size and microstructure of the PHS, scanning electron microscopy (SEM, JSM$635 \mathrm{~F}$, Jeol) was used. The specimens, with a dimension of $12 \times 8 \times 8 \mathrm{~mm}^{3}$, were subjected to a compression test
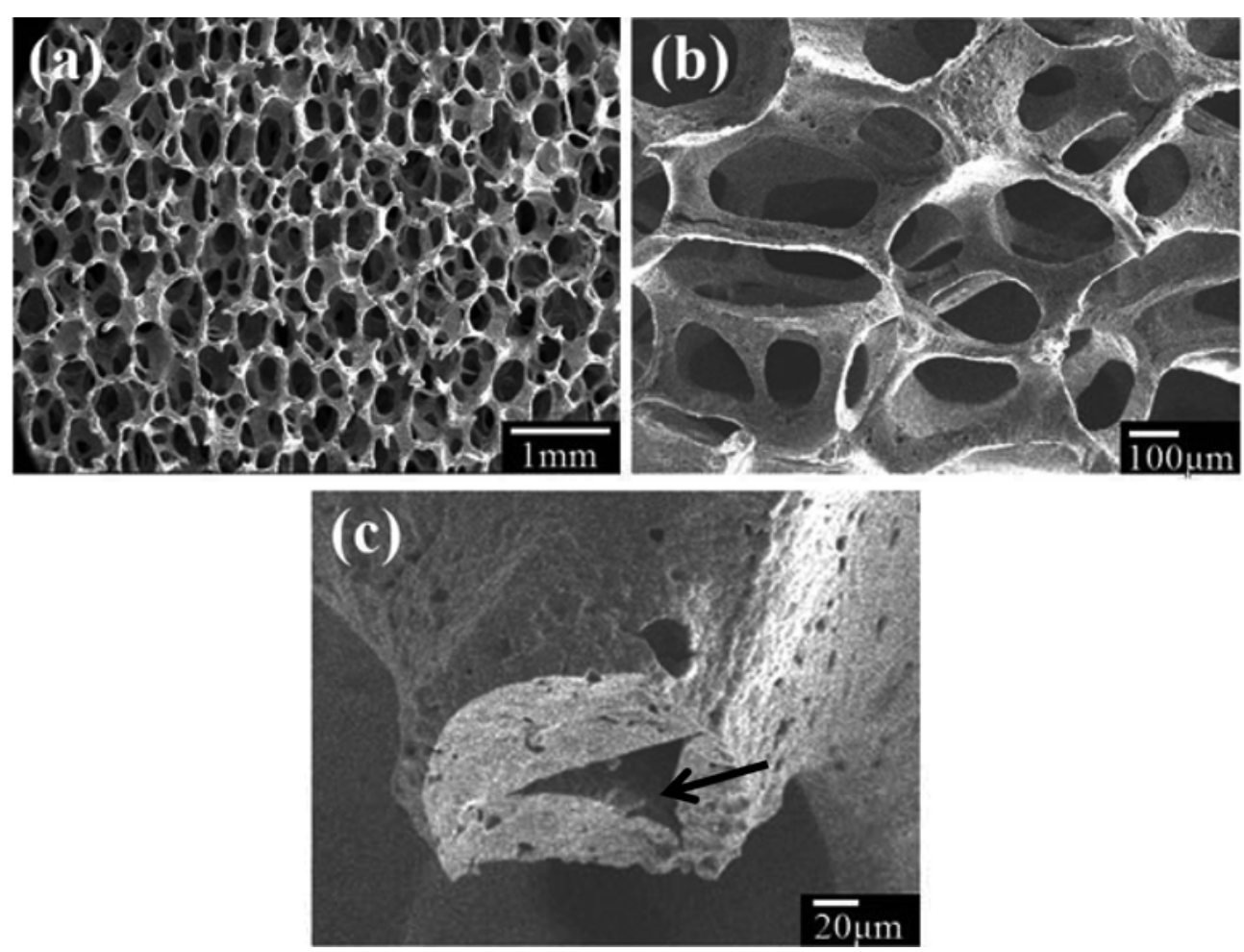

Fig. 1. SEM micrographs of the conventional sintered porous HAp scaffolds at $1300^{\circ} \mathrm{C}$ for $3 \mathrm{~h}$ (a) low magnification, (b) enlarged image, (c) cross section of the pore frame. 
using a universal testing machine (UnitechTM, R\&B, Korea) with a crosshead speed of $0.5 \mathrm{~mm} / \mathrm{min}$ in ambient conditions. The obtained stress-strain curve was used to determine mechanical properties. The compressive strength was determined from the maximum load recorded and from the slope at the initial stage, respectively.

\section{Results and Discussion}

Fig. 1 shows (a) low magnification and (b) enlarged SEM micrographs of the PHS sintered at $1300^{\circ} \mathrm{C}$ for 3 hours using the conventional sintering method and (c) a cross sectional view of the pore frame. These figures revealed that the structure of the obtained scaffolds was similar to cancellous bone, with pore sizes ranging from about 300 $\mu \mathrm{m}$ to $700 \mu \mathrm{m}$. In addition, the highly interconnected pores were found to be homogeneously distributed throughout the scaffolds. It has been shown that, in general, the pore size must be greater than $200 \mu \mathrm{m}$ to facilitate new bone formation. ${ }^{23)}$ Fig. 1(c) confirmed that the PU foam was completely removed during the burn-out and sintering process, as indicated by the arrow.

Fig. 2 shows SEM micrographs of the pore frame of the PHS when different sintering methods and temperatures were employed, i.e, conventional sintering at (a) $1100^{\circ} \mathrm{C}$ and (b) $1300^{\circ} \mathrm{C}$ for $3 \mathrm{~h}$, and microwave sintering at (c) $1100^{\circ} \mathrm{C}$ and (d) $1300^{\circ} \mathrm{C}$ with a 30 min holding time. When conventional sintering with a $3 \mathrm{~h}$ holding time at $1100^{\circ} \mathrm{C}$ (Fig. 2(a)) was used, many pores that had a diameter between $1 \mu \mathrm{m}$ and $3 \mu \mathrm{m}$ were observed. However, when the sintering temperature was increased to $1300^{\circ} \mathrm{C}$ (Fig. 2(b)), only a few pores were observed due to the growth of the grain size as well as improvements in the densification of the pore frame. The grain size varied from about 2$6 \mu \mathrm{m}$. In contrast, when microwave sintering at $1100^{\circ} \mathrm{C}$ was used, the pore frame was more densified and the average grain size (about $500 \mathrm{~nm}$ ) decreased relative to when the conventional sintered method was used (about $1 \mu \mathrm{m})$. In addition, a small number of fine pores that had a diameter of less than $700 \mathrm{~nm}$ were also observed, as shown in Fig. 2(c). However, PHS sintered at $1300^{\circ} \mathrm{C}$ using the microwave sintering method (Fig. 2(d)) had more residual pores than PHS sintered at $1300^{\circ} \mathrm{C}$ using the conventional sintering method (Fig. 2(b)), even though their particle size increased and ranged from 1 to $3 \mu \mathrm{m}$ in diameter.

Fig. 3 shows SEM micrographs of PHS fabricated using
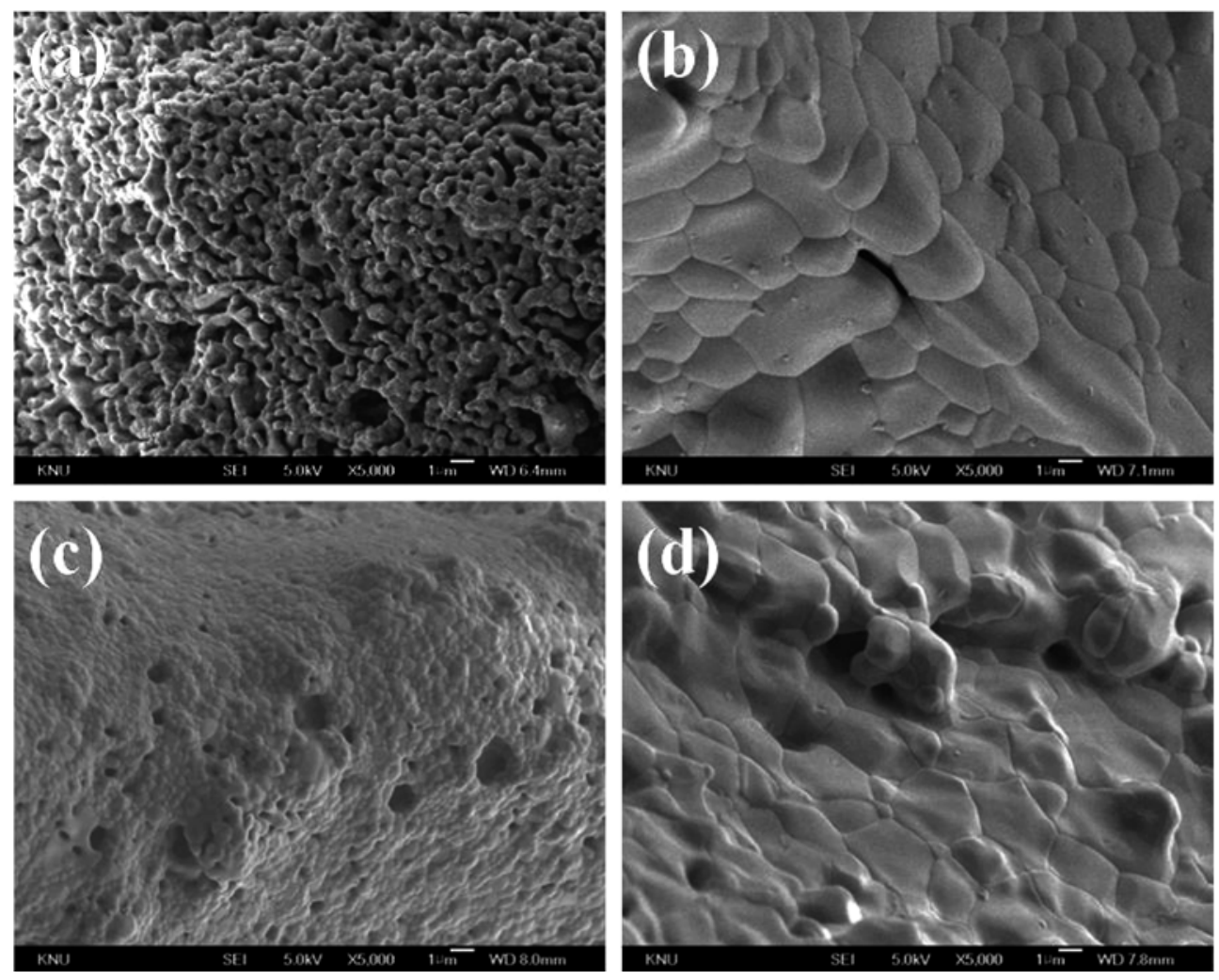

Fig. 2. SEM micrographs of the pore frame of the porous HAp scaffolds when sintered using conventional sintering for $3 \mathrm{~h}$ at (a) $1100^{\circ} \mathrm{C}$ and (b) $1300^{\circ} \mathrm{C}$, and microwave sintering for $30 \mathrm{~min}$ at (c) $1100^{\circ} \mathrm{C}$ and (d) $1300^{\circ} \mathrm{C}$. 

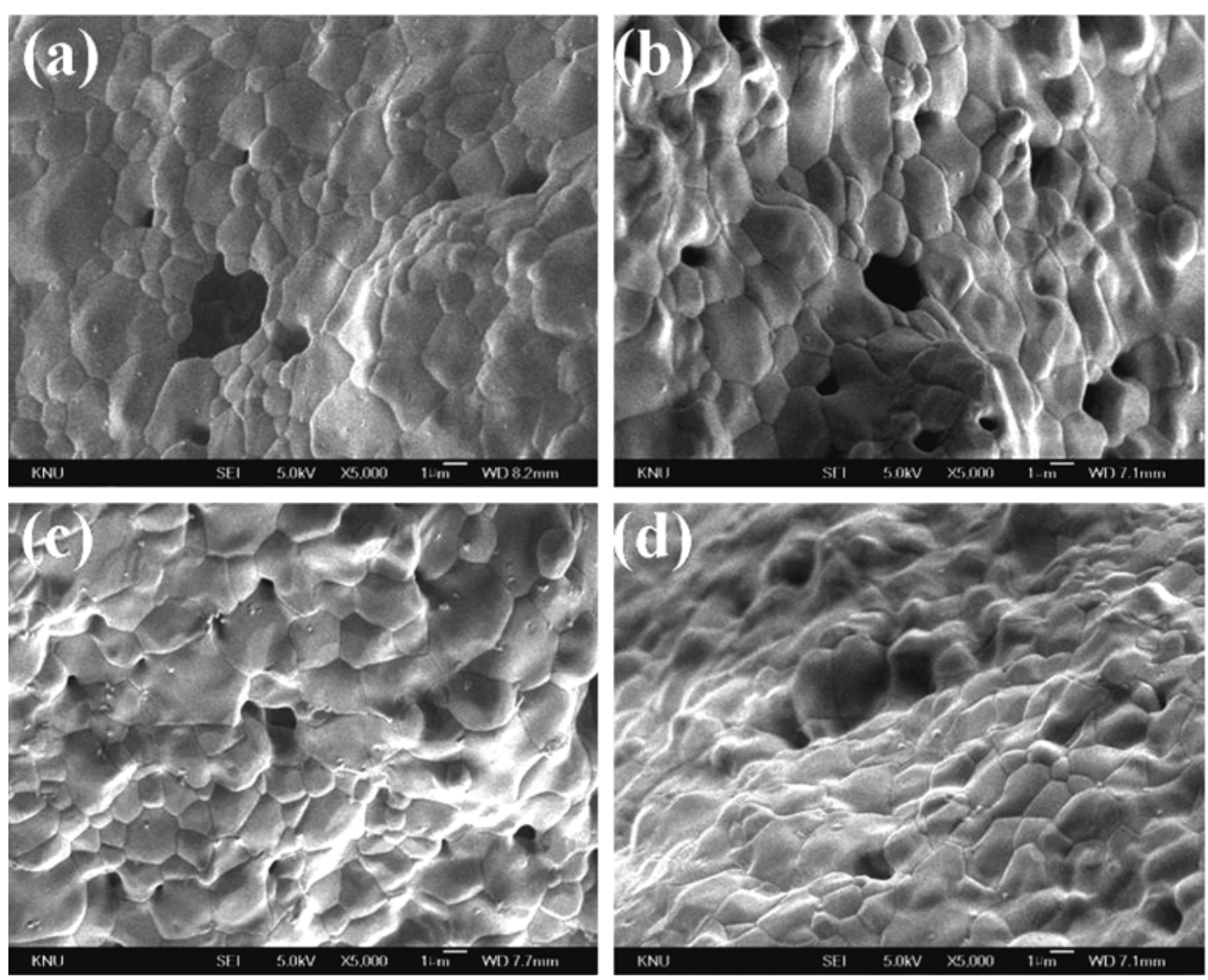

Fig. 3. SEM micrographs of the pore frame of the porous HAp scaffolds using microwave sintering at $1300^{\circ} \mathrm{C}$ and different holding times; (a) $5 \mathrm{~min} \mathrm{(b)} 10 \mathrm{~min}$, (c) $15 \mathrm{~min}$ and (d) $20 \mathrm{~min}$.

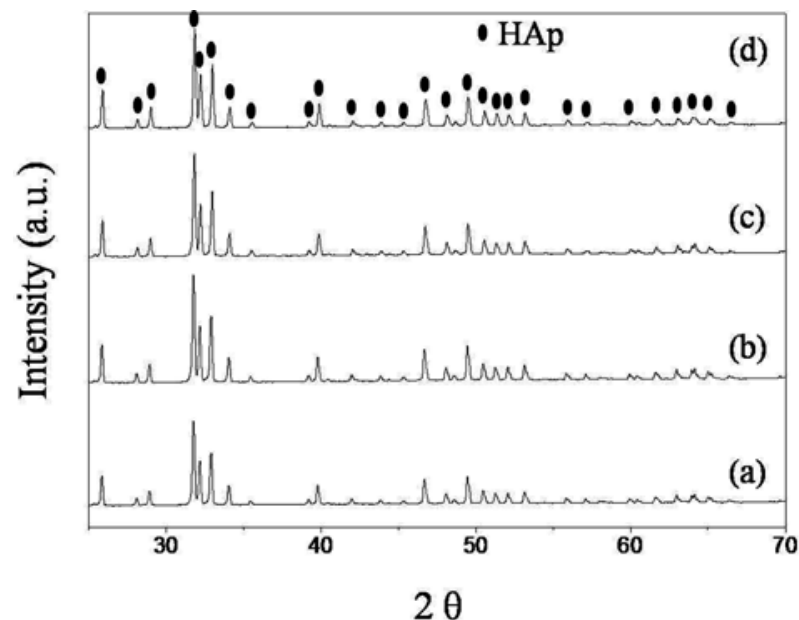

Fig. 4. XRD profiles of porous HAP scaffolds sintered by (a, $\mathrm{b}, \mathrm{c})$ microwave sintering at different sintering temperatures with a 30 min holding time and (d) conventional sintering.

the microwave sintering process at $1300^{\circ} \mathrm{C}$ and holding times of (a) $5 \mathrm{~min}$, (b) $10 \mathrm{~min}$, (c) $15 \mathrm{~min}$ and (d) $20 \mathrm{~min}$. The densification of the pore frame increased as the holding time increased, and a narrow grain size distribution was observed. In Fig. 3(d), the amount of fine pores decreased due to the grain growth of the HAp frame. The particle

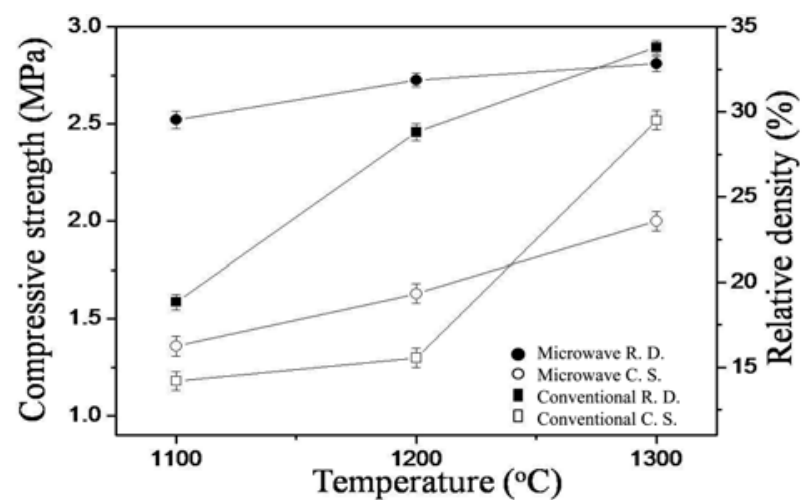

Fig. 5. Relative density and compressive strength of porous HAp scaffolds when different sintering temperatures and sintering methods were used.

size ranged from 1-3 $\mu \mathrm{m}$ in diameter.

Fig. 4 shows the XRD profiles of the porous HAP scaffolds sintered using microwave sintering at different sintering temperatures with a 30 min holding time (a, b, c) and using conventional sintering (d). Based on these XRD profiles, no new phase appeared and all HAp phases were observed at the different sintering temperatures, as shown in Fig. $4\left(\right.$ a) $1100^{\circ} \mathrm{C}$, (b) $1200^{\circ} \mathrm{C}$, and (c) $1300^{\circ} \mathrm{C}$. 


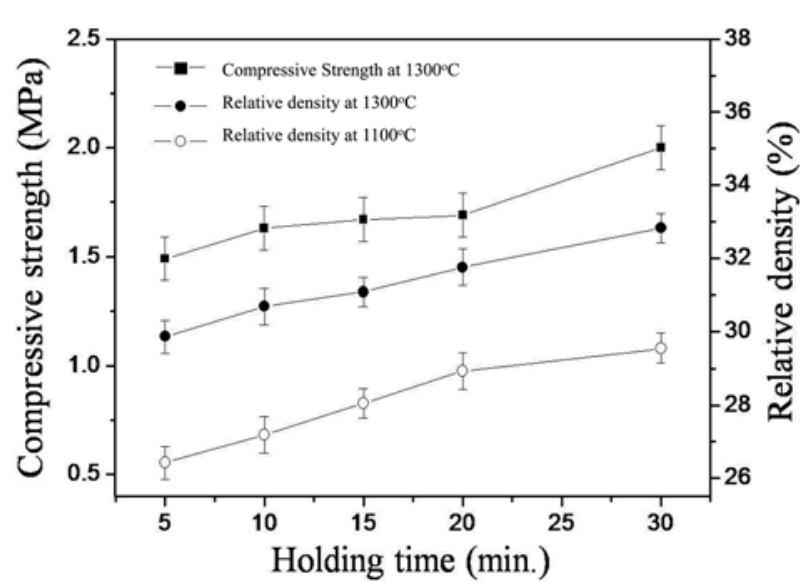

Fig. 6. Relative density and compressive strength of the microwave sintered PHS at different holding times.

In addition, all HAp phases were observed when using conventional sintering at $1300^{\circ} \mathrm{C}$ for 3 hours (Fig. $4(\mathrm{~d})$ ).

Fig. 5 shows the relative density and compressive strength of the PHS fabricated at different sintering temperatures. In these experiments, the holding time during microwave sintering was 30 minutes. The relative density of the PHS increased as the sintering temperature increased. At a sintering temperature of $1100^{\circ} \mathrm{C}$ and $1200^{\circ} \mathrm{C}$, the relative density was higher when the microwave sintering method was used than when the conventional sintering method was used. However, at a sintering temperature of $1300^{\circ} \mathrm{C}$, the relative density of the scaffolds was slightly higher when the conventional sintering method was used compared to when the microwave sintering method was used. The relative density of the conventional sintered and microwave sintered PHS were $33.8 \%$ and $32.8 \%$, respectively. The compressive strength of PHS increased as the sintering temperature was increased. At $1100^{\circ} \mathrm{C}$ and $1200^{\circ} \mathrm{C}$, the compressive strength of the microwave sintered PHS was higher than the conventional sintered PHS due to the finer grain size, as shown in Fig. 2. In addition, a higher densification was observed for microwave sintered PHS. However, at $1300^{\circ} \mathrm{C}$, the compressive strength when using microwave sintering was lower than when using conventional sintering because the conventional sintered PHS was more densified. This might be due to the longer holding time used for conventional sintering compared with that of microwave sintering. The compressive strength values of PHS were $2 \mathrm{MPa}$ and $2.6 \mathrm{MPa}$ when sintered by the microwave and conventional method, respectively. Typically, the compressive strength and compressive modulus of scaffolds fabricated using the sponge replica method was $1.2 \mathrm{MPa}$ and $8 \mathrm{MPa}$, respectively. ${ }^{24)}$

Fig. 6 shows the relative density and compressive strength of the microwave sintered PHS at different holding times. At $1100^{\circ} \mathrm{C}$, the relative density of PHS increased as the holding time increased, to a maximum value of approximately $29 \%$. However, the value of the relative density improved when the PHS was sintered at $1300^{\circ} \mathrm{C}$. This confirmed the results presented in Fig. 3. In addition, the compressive strength of the PHS also increased as holding time increased and had a maximum value at a $30 \mathrm{~min}$ holding time.

\section{Conclusion}

A Porous HAp scaffolds was successfully fabricated by microwave sintering using the replica method. The PHS had spherical interconnected pores that were approximately $300-700 \mu \mathrm{m}$ in diameter and the densification of the pore frame was improved as the sintering temperature and holding time increased. No new phases appeared at all the different sintering conditions. The relative density and compressive strength of the microwave sintered PHS sintered at $1200^{\circ} \mathrm{C}$ for $30 \mathrm{~min}$ were $31.87 \%$ and $1.63 \mathrm{MPa}$, respectively.

\section{References}

1. Y. Yan, X. Zhuo, Y. Hu, Mater. Lett., 57, 2623 (2003).

2. V. Sikavitsas, G. Bancroft, Mikos, J. Biomed. Mater. Res., 62, 136 (2002).

3. G. T. Kose, H. Kenar, Biomaterials, 24, 1949 (2003).

4. J. P. Vacanti, C. A. Vacanti, R. Langer, Principles of Tissue Engineering, p 1, Academic Press, San Diego (1997).

5. S. L. Ishaug, G. M. Crane, M. J. Miller, A. W. Yasko, M. J. Yazemski, A. G. Mikos, J. Biomed. Mater. Res., 36, 17 (1997).

6. H. Yoshimoto, Y. M. Shin, H. Terai, J. P. Vacanti, Biomaterials, 24, 2077 (2003).

7. Y. Hu, D. W. Grainger, S. R. Winn, J. O. Hollinger, J. Biomed. Mater. Res., 59, 563 (2001).

8. T. Nezu, F. M. Winnik, Biomaterials, 21, 415 (2000).

9. L. Huang, K. Nagapaudi, R. P. Apkarian, E. L. Chaikof, J. Biomater. Sci. Polym. Ed., 12, 979 (2001).

10. A. S. Goldstein, G. Zhu, G. E. Morris, R. K. Meslenyi, A. G. Mikos, Tissue Eng., 5, 421 (1999).

11. K. De Groot, Biomaterials, 1, 47 (1980).

12. M. Jarcho, Clin. Orthop. Rel. Res., 157, 259 (1981).

13. C. J. Damien and J. R. Parsons, J. Appl. Biomaterials, 2, 187 (1990).

14. M. S. Kim, J. J. Ryu, Y. M. Sung, Kor. J. Mater. Res., 19(2), 85 (2009).

15. H. W. Kim, J. C. Knowles, H. E. Kim, Biomaterials, 25, 1279 (2004). 
16. W. H. Sutton, Am. Ceram. Soc. Bull., 68, 376 (1989).

17. M. A. Willert Porada, MRS Bull., 18, 51 (1993).

18. A. C. Metaxas, J. G. P. Binner, Advanced Ceramic Processing Technology, p. 285, ed. J.G.P. Binner, Noyes Publications, New Jersey, USA (1990).

19. S. Nath, N. Shnha, B. Basu, Ceram. Inter., 34, 1509 (2008).

20. X. Wang, H. Fan, Y. Xiao, X. Zhang, Mater. Lett., 60, 455 (2006).
21. E. A. Moreira, M. D. M. Innocentini and J. R. Coury, J. Euro. Ceram. Soc., 24, 3209 (2004).

22. J. K. Han, H. Y. Song, F. Saito, B. T. Lee, Mater. Chem. Phy., 99, 235 (2006).

23. L. Cerroni, R. Filocamo, M. Fabbri, C. Piconi, S. Caropreso, S.G. Condo, Biomolecular Engineering, 19, 117 (2002).

24. Y. Zhang, M. J. Zhang, Biomed. Mater. Res., 61, 1 (2002). 